
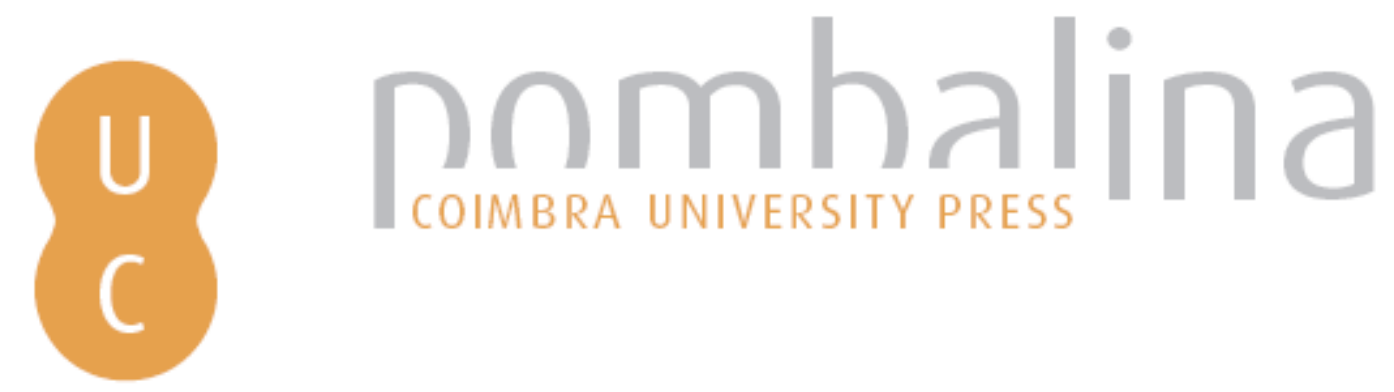

\title{
Macroespaço e microespaço no Satyricon de Petrónio: a narrativa de viagens e a tensão entre espaço aberto e fechado
}

Autor(es): $\quad$ Leão, Delfim F.; Brandão, José Luís

Publicado por: Imprensa da Universidade de Coimbra; Annablume

URL

persistente: URI:http://hdl.handle.net/10316.2/40870

DOI: $\quad$ DOI:https://doi.org/10.14195/978-989-26-1288-1_10

Accessed : $\quad$ 26-Apr-2023 10:38:33

A navegação consulta e descarregamento dos títulos inseridos nas Bibliotecas Digitais UC Digitalis, UC Pombalina e UC Impactum, pressupõem a aceitação plena e sem reservas dos Termos e Condições de Uso destas Bibliotecas Digitais, disponíveis em https://digitalis.uc.pt/pt-pt/termos.

Conforme exposto nos referidos Termos e Condições de Uso, o descarregamento de títulos de acesso restrito requer uma licença válida de autorização devendo o utilizador aceder ao(s) documento(s) a partir de um endereço de IP da instituição detentora da supramencionada licença.

Ao utilizador é apenas permitido o descarregamento para uso pessoal, pelo que o emprego do(s) título(s) descarregado(s) para outro fim, designadamente comercial, carece de autorização do respetivo autor ou editor da obra.

Na medida em que todas as obras da UC Digitalis se encontram protegidas pelo Código do Direito de Autor e Direitos Conexos e demais legislação aplicável, toda a cópia, parcial ou total, deste documento, nos casos em que é legalmente admitida, deverá conter ou fazer-se acompanhar por este aviso.

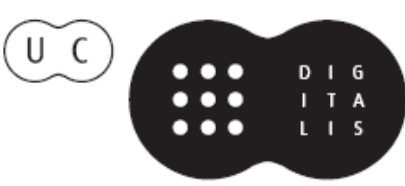




\section{Cosmópolis}

\section{mobilidades culturais às origens do pensamento antigo}

Gabriele Cornelli, Maria do Céu Fialho e Delfim Leão

\section{(coords.)}

IMPRENSA DA UNIVERSIDADE DE COIMBRA 


\section{Macroespaço e microespaço no Satyricon de Petrónio: A NARRATIVA DE VIAGENS E A TENSÃO ENTRE ESPAÇO ABERTO E FECHADO}

(Macrospace and microspace in Petronius' Satyricon: the travel narrative and the tension between open and closed spaces)

Delfim F. Leão (leo@fl.uc.pt) José Luís Brandão (jlbrandao@fl.uc.pt) Universidade de Coimbra - Centro de Estudos clássicos e Humanísticos

Resumo: A parte conservada do Satyricon de Petrónio distribui-se por três grandes espaços marcados pela influência grega em mundo romano e pelo impulso da viagem, sendo ainda cruzados pelas dinâmicas da tensão entre espaço aberto e espaço fechado, e pela presença de personagens dominadoras: a Graeca urbs onde decorre a primeira parte da narrativa, controlada pela figura do liberto Trimalquião; o mar imenso sulcado pelo barco do severo Licas; a esterilidade impudica de Crotona, onde o velho poeta Eumolpo leva a melhor sobre a turba dos heredipetae. O objetivo deste estudo é analisar de que forma o cruzamento de sensibilidades espelha a própria mundividência do império romano, ao mesmo tempo que acentua um sentimento de falência identitária e de insegurança, sublinhada pela oscilação entre espaço aberto e espaço fechado. Palavras-chave: Macroespaço; microespaço; interior; exterior; identidade; insegurança

Aвstract: The preserved part of the Satyricon develops its plot around three large spaces marked by Greek influence in the Roman world and by the impulse to travel, while at the same time being crossed by the dynamics of tension between open and closed space, and by the presence of dominant characters: the Graeca urbs, where the first part of the narrative is set, under the control of the freedman Trimalchio; the immense sea furrowed by the ship of the crude Lichas; the unashamed sterility of Crotona, where the old poet Eumolpus gets the better over the mob of heredipetae. The objective of this study is to examine how the crossing of different sensitivities reflects the worldview of the Roman Empire, while accentuating, on the other hand, a sense of collapsing identity and of insecurity, emphasized by the oscillation between open and closed spaces.

KEYwords: Macrospace; microspace; interior; exterior; identity; insecurity

\section{Enquadramento}

Quando falamos do início do império, pensamos imediatamente na pax

${ }^{1}$ Gostaríamos de expressar o nosso agradecimento ao árbitro anónimo que avaliou este estudo numa fase preliminar da publicação e a quem devemos pertinentes sugestões, que contribuíram para melhorar este trabalho. Estudo desenvolvido no âmbito do projeto UID/ ELT/00196/2013, financiado pela FCT - Fundação para a Ciência e a Tecnologia. 
Romana, na segurança dos mares, situação que favorecia a mobilidade, o comércio, a prosperidade das pessoas e das cidades. É bastante ilustrativo um passo de Suetónio no qual Augusto, já perto da morte, é agraciado por uns marinheiros de Alexandria que, com palavras e atitudes rituais, verbalizam as benesses que o princeps lhes facultou (Aug. 98.2):

Forte Puteolanum sinum praeteruehenti uectores nautaeque de naui Alexandrina, quae tantum quod appulerat, candidati coronatique et tura libantes fausta omina et eximias laudes congesserant: "per illum se uiuere, per illum nauigare, libertate atque fortunis per illum frui.

Quando atravessava, um dia, a baía de Putéolos, os passageiros e os tripulantes de um navio de Alexandria, que acabara justamente de aportar, vestidos de branco e coroados com grinaldas, não só lhe ofereceram incenso, como também o cumularam de bons augúrios e de extraordinários louvores: 'Por ele viviam, por ele navegavam; da liberdade e da felicidade por ele fruíam.'

O trecho transcrito celebra, de forma otimista, a paz universal e a vocação universalista de Augusto $^{2}$. Além da origem dos marinheiros, não só é grego o contexto do ato, como se sublinha simbolicamente a síntese entre elementos gregos e latinos sob a autoridade do imperador: diz o biógrafo que o princeps promove uma permuta de vestuário e de língua entre as duas etnias e assiste ao costume grego dos jogos dos efebos de Cápreas (Suetónio, Aug. 98.3).

A facilidade de circulação é celebrada ainda no tempo dos Flávios pelo poeta Marcial, que vê a justificação para o seu êxito pessoal na vocação universalista e integradora de Roma, uma vez que possibilita a difusão dos seus escritos na Gália (7.88), ou em terras mais distantes: bic est quem legis ille, quem requiris, / toto notus in orbe Martialis (1.1.1-2) ('este é aquele que lês, aquele que reclamas, / Marcial, conhecido em todo o mundo'). Ou, de modo semelhante: ore legor multo notumque per oppida nomen / non expectato dat mibi fama rogo (3.95.7-8) ('sou lido por muitas bocas e um nome conhecido através das cidades / me dá a fama, sem esperar pela pira») ${ }^{3}$.

O poeta escreve numa época em que, depois da lembrança dos excessos de Nero e da guerra civil de 68-69 (em que quatro imperadores se sucederam no trono imperial, impostos mais pelo Orbe que pela Urbe), os Flávios pretendiam

${ }^{2} \mathrm{O}$ passo evoca provavelmente uma cerimónia litúrgica, como sugere o aparato (roupas, flores, incenso) e o ritmo da invocação. Para Rocca-Serra 1974: 671-680, será a expressão de um dos temas da propaganda de Augusto (a paz universal e a segurança dos mares) e que subentende a assimilação do príncipe a Júpiter, como causa última. Segundo Benario 1975: 84, é reflexo da afeição e aprovação generalizada do Império à obra de Augusto e à estabilidade do governo (prometida em Suetónio, Aug. 28.2).

${ }^{3}$ Cf. 6.64. 
Macroespaço e microespaço no Satyricon de Petrónio: a narrativa de viagens e a tensão entre espaço aberto e fechado

operar a restauração da ordem e da beleza de Roma, numa repristinação propagandística ao modelo augustano ${ }^{4}$. E se há um monumento icónico da universalidade do império é sem dúvida o Coliseu ou Anfiteatro Flávio, obra que se tornará um símbolo difusor do poder e de propaganda, replicado nas cidades provinciais, mas que também se apresenta como síntese da força centrípeta de Roma e uma espécie de microcosmo do mundo romano. A construção aparece, logo à nascença, associada a motivos de proveniência diversa, desde a exibição de feras de toda a espécie ${ }^{5}$ à convergência multicultural do público. Com efeito, no epigrama de abertura do Liber Spectaculorum, cuja publicação celebra a inauguração do monumento em 80 d.C., Marcial evoca cinco maravilhas do mundo antigo, para, no final (Spect. 1.7-8), proclamar a superioridade daquele anfiteatro, cuja denominação posterior, Coliseu, devida à proximidade do colosso de Nero, haverá de evocar também o de Rodes ${ }^{6}$. E, no terceiro epigrama, o Coliseu torna-se um espaço de cosmopolitismo que abarca a diversidade cultural e étnica do império, visível nas origens exóticas dos presentes. A passagem da diversidade à unidade é simbolizada na figura do imperador: o variado linguajar que ressoa transforma-se numa só língua quando se trata de aclamar Tito como Pai da Pátria (Marcial, Spect. 3.12). Destaca-se assim o papel unificador do imperium, exercido pela função administrativa do imperador, pela língua e pela arquitetura, claros fatores de mundialização ${ }^{7}$.

A mobilidade física ajudava a fomentar a mobilidade social. A promoção das elites locais através da concessão da cidadania é uma estratégia de domínio e romanização ${ }^{8}$. E, em Roma, a substituição das famílias senatoriais por novos membros (em parte oriundos das províncias) dá-se a um ritmo que surpreende; a classe equestre é um vasto grupo, com cargos reservados aos seus membros; os veteranos do exército podiam tornar-se em terratenentes com estatuto em comunidades espalhadas pelo império ${ }^{10}$; e os libertos em especial prosperavam,

${ }^{4}$ Cf. Suetónio, Ves. 8.1. Vespasiano justificava a construção do Anfiteatro como sendo já um projeto de Augusto (Suetónio, Ves. 9.1)

${ }^{5}$ Cf. Suetónio, Tit. 7.3; Marcial, Spect. 9; 10; 17-19; 22-23.

${ }^{6}$ As maravilhas referidas são as seguintes: pirâmides do Egito; jardins suspensos da Babilónia; templo de Diana, em Éfeso; altar feito de chifres entrelaçados, existente em Delos e dedicado a Apolo; Mausoléu de Halicarnasso. Para um conspecto da tradição relativa às maravilhas do Mundo Antigo, com elenco das fontes, tradução e análise, vide Ferreira e Ferreira 2009.

${ }^{7}$ Vide Brandão 2012: 135-137 e 153-154; Fitzgerald 2007: 34-43.

8 Tomando como exemplo o nosso território e concretamente no que diz respeito a magistrados de Olissipo, vide Mantas 2005 (particularmente 29-30, a propósito de uma inscrição de um magistrado flâmine de Germânico e de Lívia); e sobre uma hipótese de antecipação na atribuição do direito latino a comunidades lusitanas, Mantas 2010.

975 em 100 por cada geração segundo Garnsey e Saller 1991: 141. Cláudio é conhecido pela abertura na concessão da cidadania, bem como da dignidade de senador, inclusivamente a filhos de libertos: cf. Suetónio, Cl. 22.1.

${ }^{10}$ Vide Garnsey e Saller 1991: 132-133. 
e tinham mesmo maiores possibilidades de êxito do que os humildes de nascimento livre, uma vez que recebiam do seu patrono o capital inicial para empreendimentos no comércio ou manufatura. Eram, por assim dizer, bafejados pela fortuna do patrono. Com efeito, a manumissão constituía uma forma de transferência de riqueza, a par da herança paterna, da adoção, ou da inclusão em testamentos ${ }^{11}$.

Mas a verdade é que o preconceito em relação à origem servil os perseguia ${ }^{12}$, embora o direito previsse a atribuição de privilégios que, em diferentes graus, os aproximava dos ingenui $i^{13}$. Mesmo os libertos poderosíssimos, invejados e odiados, que a partir de Cláudio dirigem os gabinetes imperiais, a quem se chega a outorgar o «direito de nascimento livre», não podem evitar a pecha ${ }^{14}$. Porque a questão é tanto social como moral: possuem a riqueza mas o espírito continua, em essência, a ser o de um liberto ${ }^{15}$. Esta mentalidade aristocrata encontra pleno eco na construção de figuras célebres de novos-ricos, como sejam o Trimalquião de Petrónio ou o Zoilo de Marcial ${ }^{16}$, onde o sal se mistura com pessimismo e sentimento de castração. Ora é precisamente a sensação de acentuada falência da missão civilizadora da Roma neroniana, tal como vem retratada no Satyricon de Petrónio, que colherá agora a nossa atenção.

Com efeito, a parte conservada do Satyricon de Petrónio distribui-se por três grandes espaços profundamente marcados pela influência grega em mundo romano e pelo impulso da viagem, bem como pela tensão entre espaço aberto e espaço fechado, nos quais é notório o controlo exercido por personagens dominadoras ${ }^{17}$. Desta forma, a designação genérica de Graeca urbs atribuída ao espaço urbano onde decorre a primeira parte da narrativa salienta a influência assumidamente grega em espaço romano. Esta primeira parte da obra é dominada pela figura do liberto Trimalquião, cuja casa assume os contornos de uma micrópolis com regras próprias que vinculam moradores e visitantes à mesma lógica de um

${ }^{11}$ Como sublinham Garnsey e Saller 1991: 147-150. No que diz respeito aos libertos no atual território nacional, vide o estudo comparativo de registos epigráficos de Mantas 2002.

${ }^{12}$ Cf. Tácito, Ann. 13.26-27.

${ }^{13}$ Como o ius aureum anulorum, que aproximava o liberto dos ingénitos livres, sem os libertar dos direitos do patrono, e a restitutio natalium, que os libertava dos direitos dos patronos. Para uma síntese das questões jurídicas relacionadas com a manumissão e dos diversos estatutos dos libertos e relação com os patronos, vide Guillén 2009: 249-253.

${ }^{14}$ Sobre as honras concedidas a Palante e Narciso por Cláudio, que paradoxalmente se comportava de forma servil, cf. Suetónio Cl. 28-29.1. Plínio (Ep. 7.28-29) indigna-se perante uma inscrição que celebra as honras concedidas a Palante.

${ }^{15}$ Como diz Séneca (Ep. 27.5) a propósito de Calvísio Sabino. Cf. Horácio Sat. 2.8, a propósito do mau gosto de Nasidieno. Uma solução para de algum modo premiar o êxito dos libertos foi a criação dos colégios de Augustales nas cidades de Itália e das províncias ocidentais. Vide Garnsey e Saller 1991: 144-145.

${ }^{16}$ Vide Leão 2004; Brandão 2012: 143-144.

${ }^{17}$ Sobre o tema da viagem no Satyricon (em paralelo com o mesmo tema na Eneida e no Asinus Aureus), vide Teixeira 2007: 233-368. 
espaço marcado pela imagem do labirinto. Numa outra dimensão espacial, o mar imenso, através do qual Encólpio e Gíton buscam a esperança da evasão, acaba subitamente por circunscrevê-los ao barco do severo Licas, que constitui em si mesmo também uma micrópolis ou um pequeno Estado autocrático, cuja ordem será profundamente perturbada pela descoberta dos passageiros clandestinos, que descambará em paródica guerra civil. Por último, a esterilidade impudica de Crotona, onde o velho poeta Eumolpo leva a melhor sobre a turba dos heredipetae, recria um cenário em que, ao contrário dos dois anteriores, o engano é assumido de forma pública e descarada, embora também aqui vários episódios sublinhem a tensão entre espaço aberto e espaço fechado (como a aventura de Encólpio/Polieno com as sacerdotisas ou o encontro de Eumolpo com os filhos de Filomela).

Por outro lado, o tema da viagem estimula, do ponto de vista narrativo, a mudança de enquadramento espacial, ao mesmo tempo que acentua um cruzamento de sensibilidades (grega e romana, escravos e libertos, eruditos e novos-ricos) que espelha a pujança cosmopolita do império romano. No entanto, se o tópico da viagem e a variação de enquadramentos cénicos são, em si mesmos, elementos positivos, pois cadenciam a narrativa e colocam as personagens (e leitores) perante novos desafios, não deixam ainda assim de exprimir, ao mesmo tempo, um sentimento de falência identitária e de insegurança omnipresente, acentuada pela ténue e muito instável separação entre espaço aberto e espaço fechado, sublinhado pela inerme fronteira decorrente do simbolismo da porta.

Este estudo pretende, portanto, abordar as manifestações de cosmopolitismo itinerante que acompanham as principais personagens da obra (Encólpio, Gíton e Eumolpo), cruzando-as com a dinâmica disruptiva de espaços mais ou menos amplos que se combinam de formas várias para recriar um universo referencial profundamente marcado pela imagem da instabilidade.

\section{O MACROESPAÇO DA OBRA E O MICROESPAÇO DE DOMINADORES E DOMINADOS}

Um traço comum a Trimalquião, Licas e Eumolpo reside no facto de todas estas personagens estarem relacionadas com a imagem da morte ou da finitude — seja de forma real, anunciada ou simplesmente encenada —, ilustrando assim um tema recorrente na obra petroniana, que acentua um sentimento geral de caducidade humana $^{18}$. Por outro lado, essas figuras aparecem igualmente ligadas, de preferência, a determinados espaços urbanos: Licas, embora morra no mar,

18 Sobre esta questão, vide Leão 2013, estudo do qual são recuperados alguns dos argumentos agora apresentados. 
provém de anteriores aventuras, que talvez se tenham passado em Massília ${ }^{19}$; Trimalquião surge dominador na Graeca urbs e, depois do seu funeral fictício, quase não volta a ser referido; Eumolpo, que conhece Encólpio e Gíton também na Graeca urbs, protagoniza a sua maior aventura conhecida em Crotona, lugar onde se sugere que acabará por encontrar a morte, evocada pelo testamento que impõe a cena final de necrofagia com que pretende ludibriar os heredipetae. Há assim, no enquadramento narrativo destas personagens, uma ligação clara ao cosmopolitismo do império romano, que potencia a mobilidade e a mudança. Delas decorre uma experiência da vida que torna estas personalidades, até certo ponto, em ilustrações de um determinado tipo de sapientia que tanto Trimalquião como Eumolpo procuram cultivar em vários momentos da sua atuação, ainda que com resultados nem sempre bem conseguidos, contribuindo assim para a dimensão paródica e satírica do universo recriado no romance. Licas não exibe, por si próprio, este mesmo brilho (pseudo)intelectual, mas a morte efetiva a que se verá sujeito acabará por inspirar noutros - especialmente em Encólpio - amargas reflexões sobre a existência humana que ajudam a cumprir, à sua maneira, este mesmo perfil de uma sabedoria prática que ora procura impor-se pelas palavras ora decorre da vivência de situações extremas, mas que se traduz também, de forma positiva, na expressão de um conhecimento da vida marcado pela mobilidade física e social (neste último caso, notavelmente ilustrada por Trimalquião).

\subsection{Trimalquião: do macroespaço da Graeca urbs ao microespaço autocrata da Cena}

Um tema tradicional, já brevemente evocado na secção anterior e que encontra um notável tratamento no Satyricon, é o motivo dos 'caçadores de heranças'. O mote dos heredipetae (explorado em particular em Crotona) pressupõe três realidades diferentes, mas correlativas: o poder inerente a quem é rico e a sedução que a riqueza exerce sobre quem procura insinuar-se junto dos poderosos; a hora da morte, mais ou menos veladamente esperada pelas pessoas que gravitam à volta da vítima eleita; a falta de herdeiros legítimos, cuja existência comprometeria a possibilidade de se vir a ser contemplado no testamento. Não surpreende, por isso, que este motivo se encontre presente, no todo ou em parte, nas aventuras que envolvem as três personagens que marcam os macroespaços da obra, embora com especial impacto nos casos de Trimalquião e Eumolpo. A crítica tem estudado, sobretudo, Trimalquião, uma atenção justamente atribuída a esta criação petroniana incontornável, protagonista de um episódio igualmente

${ }^{19}$ É certo que o encontro de Encólpio com Licas também pode ter-se verificado na Campânia ou de qualquer modo, como a profissão de armador requer, em uma cidade portuária. Sobre esta hipótese de reconstituição de eventos perdidos, vide Sullivan 1977: 30-32. 
Macroespaço e microespaço no Satyricon de Petrónio: a narrativa de viagens e a tensão entre espaço aberto e fechado

famoso e único, a Cena Trimalchionis, que funciona, de resto, como uma micrópolis autocrática dentro do ambiente mais amplo da Graeca urbs ${ }^{20}$. Com efeito, a riqueza do liberto - logo secundada pela sua ostentação - é imensa ${ }^{21}$. Muitos são os pormenores, ao longo do Festim, que salientam essa realidade ${ }^{22}$. Bastará evocar um deles, a título meramente ilustrativo, facultado por Hérmeros, um conviva que tinha explicado a Encólpio o jogo de palavras encoberto em carpe e lhe dera informação sobre a laboriosa Fortunata, a esposa de Trimalquião ${ }^{23}$. Hérmeros fala do anfitrião nestes termos (37.8-10):

Ipse Trimalchio fundos habet, qua milui uolant, nummorum nummos. Argentum in ostiarii illius cella plus iacet, quam quisquam in fortunis habet. Familia uero babae babae, non mehercules puto decumam partem esse quae dominum suum nouerit. Ad summam, quemuis ex istis babaecalis in rutae folium coniciet. Nec est quod putes illum quicquam emere. Omnia domi nascuntur: lana, credrae, piper; lacte gallinaceum, si quaesieris, inuenies.

Quanto a Trimalquião, tem propriedades por onde os milhafres podem espraiar o voo, rios e rios de dinheiro. Há mais prata pelo chão do quarto do seu porteiro, que muito boa gente tem no seu património. Quanto à criadagem - ora, ora! Tenho para mim, caramba, que nem a décima parte conhece o patrão. Numa palavra: é bem capaz de enfiar na ponta dum chinelo qualquer um desses lambe-botas. E não vás pensar que ele compra seja o que for. É tudo produção da casa: lã, limões, pimenta... leite de galinha, se o pedires, aí o poderás encontrar.

É provável que a descrição esteja um tanto magnificada, pela evidente admiração que Hérmeros nutre pelo êxito conseguido por Trimalquião. No entanto, as afirmações que faz parecem confirmar-se ao longo do Festim: a referência à abundância de objetos em prata é um eco das primeiras impressões de Encólpio ao entrar na casa do seu anfitrião (28.8); por outro lado, a ideia de que a criadagem era tão numerosa que a maior parte nem conhecia o senhor também se afigura congruente com o relatório de contas exposto no decurso

${ }^{20}$ Sobre a forma como o ambiente fechado da Cena está sujeito à omnipotência de Trimalquião e à sua tentativa de controlar os elementos definidores do sistema de mobilidade (espaço, tempo e movimento), vide Teixeira 2005; 2007: 262-300; 2008: 59-79.

${ }^{21}$ Não são convincentes tentativas, como a de Baldwin 1978, para diminuírem drasticamente essa realidade.

${ }^{22}$ E.g. 28.7-8; 29.3-8; 30.2-3; 32.4; 33.2; 34.2-3; 47.11-13; 52.1. Algumas das referências são, seguramente, hiperbólicas e ilustrativas, portanto, da megalomania do liberto: 48.1-3; $53.1-10 ; 67.7-8$.

${ }^{23} 36.5-8$ e 37.1-8, respetivamente. A propósito do senhor da casa, tinha já afirmado (37.6): ipse nescit quid habeat, adeo saplutus est ('ele nem sabe o que possui, podre de rico como é). Para as citações latinas, adota-se o texto de Müller e Ehlers 1995; para a tradução, Leão 2006. 
da Cena (53.1-10), mesmo descontando uma larga margem para o exagero. Por tudo isto, Hérmeros pode afirmar, com satisfação: quemuis ex istis babaecalis in rutae folium coniciet. O poder do anfitrião está presente, inclusive, no próprio nome que Petrónio the atribuiu, certamente para sublinhar este traço da sua personalidade. Com efeito, o termo 'Trimalquião' significará algo como 'três vezes rei' ou 'três vezes poderoso' ${ }^{24}$.

Há na Cena um passo particularmente rico para a história do fundo económico e social deste período da época imperial, que espelha, igualmente, a mobilidade social potenciada pelo sucesso nos negócios, visível em especial na figura de alguns libertos ${ }^{25}$. Trata-se do momento em que Trimalquião, zangado com Fortunata, começa a ceder às instâncias dos amigos para que esqueça o incidente familiar. Esporeado por esta escaramuça doméstica que lhe garantira, uma vez mais, a atenção geral, o anfitrião resolve narrar a história da sua vida, a qual constitui um exemplo de aplicação e de pertinácia - o coricillum que pulsa em homens de fibra, algo de que se não podem ufanar os scholastici, cuja (pretensa) erudição lhes não permite viver acima do patamar dos arranjos de circunstância, como o que os levara à micrópolis constituída pela casa de Trimalquião. Essa capacidade empreendedora está bem patente nas palavras que sintetizam o êxito empreendedor do liberto (76.8): quicquid tangebam, crescebat tanquam fauus ${ }^{26}$. E Trimalquião tem plena consciência da importância que a riqueza acumulada representa para o juízo da sociedade (77.6):

Credite mibi: assem habeas, assem ualeas; habes, habeberis. Sic amicus uester, qui fuit rana, nunc est rex.

Vão por mim: pataca que tenhas, pataca que vales; na conta do que tiveres, é nessa que serás tido. Assim o vosso amigo, que já foi rã, agora é rei.

Por isso, não tem ilusões: sabe que a consideração de que desfruta e os sorrisos amáveis que todos lhe dispensam se dirigem, de preferência, ao seu dinheiro. Por esse motivo, se estivesse certo de vir a ser recordado com genuína

${ }^{24}$ Cf. Schmeling 1969: 9; 2011: 84. A preocupação do liberto em se rodear de nomes propiciatórios (como a esposa Fortunata ou o puer delicatus Creso) remete, em última análise, para a sua superstição, um traço que partilha aliás com os demais ex-escravos. Sobre o nome de Trimalquião, vide ainda Walsh 1970: 114; Anderson 1981: 50. Interpretação depreciativa do nome em Castorina 1973: 22-23 e n. 16. Sobre a possível simbologia do número três e do esquema da triplicação aplicado a vários dos episódios da obra, vide Leão 1998: 57-58. Considerar, ainda, sobre os três níveis de leitura que permite o banquete do liberto, o artigo de Martin 1988: 242-244.

${ }^{25}$ A riqueza dos libertos torna-se proverbial, sendo conseguida por vezes de forma indigna de homens livres. Por isso, cedo deu azo também à expressão de lugares-comuns de novo-riquismo. Sobre a afluência de libertos a Roma e a expressão literária da crítica ao uso que dão à sua riqueza em Séneca, Petrónio, Marcial e Juvenal, vide Guillén 2009 254-257; Brandão 2012 143-144.

26 'Coisa em que eu pusesse as mãos, medrava que nem favo de mel.' 
Macroespaço e microespaço no Satyricon de Petrónio: a narrativa de viagens e a tensão entre espaço aberto e fechado

saudade, depois de morto, talvez não visse a necessidade de fazer um mausoléu tão sumptuoso como o que arquitetara com Habinas, o empresário de pompas fúnebres que se vem juntar mais tarde aos convivas. $\mathrm{O}$ objetivo é deixado bem claro (71.5-6 e 71.11):

Respiciens deinde Habinnam 'quid dicis' inquit 'amice carissime? Aedificas monumentum meum, quemadmodum te iussi? Valde te rogo ut secundum pedes statuae meae catellam pingas et coronas et unguenta et Petraitis omnes pugnas, ut mihi contingat tuo beneficio post mortem uiuere. [....] Horologium in medio, ut quisquis horas inspiciet, uelit nolit, nomen meum legat.

Fixou então os olhos em Habinas e perguntou:

- E tu que dizes, meu amigo do peito? Vais tratar de me construir o monumento fúnebre, tal como eu te pedi? Peço-te encarecidamente que junto aos pés da minha estátua faças representar uma cachorrita, coroas de flores, vasos de perfume e ainda todos os combates de Petraites, a fim de que eu consiga, através da tua benevolente aplicação, a graça da vida depois da morte. [....] E um relógio ao centro, para que quem for ver as horas, com ou sem vontade, tenha de ler o meu nome.

O novo-rico pretende que o seu túmulo seja um verdadeiro monumentum, isto é, algo que lhe assegure um lugar na memória dos vivos ${ }^{27}$. Poderá dizer-se, com razão, que estas ideias mais não exprimem do que a usual jactância do liberto. Mas verdade é, também, que Trimalquião sentia a mágoa de não ter ninguém que continuasse o seu nome e perpetuasse o império por ele conquistado ${ }^{28}$. Trata-se de um homem que conseguiu singrar na vida, até atingir um lugar de relevo no seu meio, graças à riqueza e ao poder de que a Fortuna o dotou. Apesar de tudo, é um ser inquieto. Sente que a atenção que lhe dispensam, salvo raras exceções, é mais interesseira que genuína. A sombra da morte tolda-lhe, cada vez mais, os dias, e o liberto ensaia a ilusão de controlar esse momento final, procurando torná-lo presente e adivinhar os efeitos que irá provocar. Mas pesa-lhe que toda a sua vida caia no esquecimento. Por isso, procura conquistar um lugar no coração dos mais diretos colaboradores e garantir a perenidade no seu monumentum. Desta forma, apesar de o seu poder se estender pelo macroespaço da Graeca urbs e de a Cena assumir, de forma clara, os contornos de uma micrópolis dominada pela autoridade omnipresente do liberto, a imagem da morte que, de forma progressiva, toma conta da atmosfera de Festim e inclusive motiva o seu termo sugere que este espaço interior acaba por tornar-se simbolicamente na própria tumba permanente do Trimalquião, selando no tempo a sua existência e personalidade.

\footnotetext{
${ }^{27}$ Cf. Schlant 1991: 51-53.

${ }^{28}$ Revela esse pesar, quando se zanga com Fortunata (74.15-16).
} 
Alargando agora a análise ao contexto histórico de produção do Satyricon, este microcosmos autocrático e fechado definido pela casa de Trimalquião e pela Cena lembra a tradição relativa à descrição da famosa Domus Aurea de Nero, lançada em volta de uma lago central e dominada pelo colosso do imperador, como regista Suetónio (Nero 31.1-2):

Vestibulum eius fuit, in quo colossus $C X X$ pedum staret ipsius effigie; tanta laxitas, ut porticus triplices miliarias haberet; item stagnum maris instar, circumsaeptum aedificiis ad urbium speciem; rura insuper aruis atque uinetis et pascuis siluisque uaria, cum multitudine omnis generis pecudum ac ferarum. In ceteris partibus cuncta auro lita, distincta gemmis unionumque conchis erant; cenationes laqueatae tabulis eburneis uersatilibus, ut flores, fistulatis, ut unguenta desuper spargerentur; praecipua cenationum rotunda, quae perpetuo diebus ac noctibus uice mundi circumageretur; balineae marinis et albulis fluentes aquis. Eius modi domum cum absolutam dedicaret, hactenus comprobauit, ut se diceret quasi hominem tandem habitare coepisse.

Era tal o vestíbulo que nele se erguia um colosso de cento e vinte pés com os traços do dono; eram tão grandes as áreas, que continham um triplo pórtico de uma milha; e também um lago à imitação de um mar, rodeado de construções a fingir de cidades; e, ainda por cima, diversos campos, de cultivo e de vinhas, de pastagens e florestas, com uma vasta fauna de todo o tipo, de gado doméstico e animais selvagens. Nas restantes partes, tudo estava recoberto de ouro e adornado de gemas e de conchas de pérolas. As salas de jantar tinham os tetos artesoados com placas de marfim móveis, de modo a espalhar flores do alto, e perfuradas, para lançar borrifos de perfumes. A sala de jantar principal era arredondada, para poder rodar continuamente, dia e noite, a fazer as vezes de mundo. Nos banhos corria água do mar e de Álbula. Concluída deste jeito a moradia, ao inaugurá-la, deu a sua aprovação, limitando-se a dizer que finalmente começava a habitar que nem um homem!

Os excessos de Nero oprimem os cidadãos, com a agravante de que se passa do plano ficcional para o cívico, ou pelo menos biográfico. Tratava-se da realização de uma fantasia de um tirano: uma villa no centro da cidade (cf. Tácito, Ann. 15.42.1), o que causava indignação, pela lembrança do incêndio e pelas expropriações que o superbus ager implicara, como nota Marcial (Spect. 2.8) ${ }^{29}$ e como sugerem os grafitos de protesto ${ }^{30}$. A representação de cidades e campos ao redor do lago central corresponderia, para Grimal, a uma espécie de microcosmos do mundo mediterrâneo ${ }^{31}$. As inovações mecânicas das salas de jantar, sinais de

\footnotetext{
${ }^{29}$ Vide Aiardi 1978: 99.

${ }^{30}$ Cf. Suetónio, Nero, 39.2.

${ }^{31}$ Vide Grimal 1955: 16-17. Cf. Marcial Spect. 2.5-6.
} 
Macroespaço e microespaço no Satyricon de Petrónio: a narrativa de viagens e a tensão entre espaço aberto e fechado

extravagância e do caráter histriónico do imperador - com dispositivos que permitiam espalhar flores e perfumes sobre os convivas -, têm claros ecos em Petrónio (Sat. 60) e Séneca (Ep. 90.15)32. O paralelismo vai mais longe: no cume da gradação, estava a praecipua cenatio rotunda, que girava em representação do universo e do devir do tempo ${ }^{33}$.

É interessante notar que o Coliseu será o símbolo oposto a esta centralização autocrática, segundo a propaganda dos Flávios visível em Marcial. No segundo epigrama do já referido Liber spectaculorum, o poeta louva as construções que se elevaram no lugar da Domus Aurea, a extravagante uilla, símbolo da arrogância tirânica de Nero, a culminar numa expressão que traduz a propaganda flaviana (Spect. 2.11): reddita Roma sibi est ('Roma foi restituída a si mesma'). O teor laudatório do epigrama centra-se, pois, na metamorfose de espaço fechado em espaço aberto de circulação, de convívio e de espetáculo; e na transformação dos deleites de um soberano (dominus) em deleites do populus (Spect. 2.12).

\subsection{Licas: do macroespaço evasivo do mar ao microespaço fatal do barco}

Apesar de ter muito menos peso na obra do que a figura anterior, em Licas a questão do poder e da morte encontra-se também gravada com incontestável clareza, bem como a expressão da dinâmica macroespaço vs microespaço. Uma vez que Licas e Trifena integraram, forçosamente, aventuras da parte não conservada do Satyricon, a informação disponível sobre estas personagens é menos abundante, mas ainda assim suficiente para ilustrar um padrão referencial semelhante.

Depois do tumulto vivido na locanda, e de novo causado pela disputada beleza de Gíton, este último e o ferido amante Encólpio resolvem embarcar, juntamente com o poeta Eumolpo e o seu mercenário Córax, num navio que se prepara para zarpar, numa tentativa de escaparem às contrariedades vividas na Graeca urbs, em especial dos riscos da desavença com Ascilto ${ }^{34}$. A bordo, o jovem Encólpio tenta atrair o sono, mas ainda não adormecera e já o afligia um pesadelo, infelizmente de contornos bem nítidos e persuasivos. Vozes conhecidas, vindas diretamente de um passado do qual procuravam fugir, deixavam-no em alvoroço, tal como a Gíton. Urgia perguntar a Eumolpo, com fugidia esperança, o nome do dono do barco onde incautamente se tinham deixado encerrar, quando procuravam a salvação do mar aberto. Eumolpo levou a mal

\footnotetext{
${ }^{32}$ Segundo a História Augusta, um artifício semelhante será, mais tarde, atribuído à sala de jantar de Heliogábalo (SHA Hel. 90.15).

${ }^{33}$ Talvez se possa, por isso, falar de paródia de Nero em Petrónio, ou talvez se trate de topoi retóricos ou literários que já existiam e eram usados em situações similares. Vide Aiardi 1978 : 95-96; Morford 1968 : 158-179; Blaison 1998 : 621-623; Brandão 2009: 223-230.

${ }^{34}$ Para uma análise pormenorizada destas peripécias vividas na segunda parte da estada na Graeca urbs e da travessia na nau de Licas, vide Teixeira 2007: 301-344.
} 
que o importunassem e foi dizendo, em tom de reprimenda (100.6-7):

Hoc erat — inquit - quod placuerat tibi, ut subter constratum nauis occuparemus secretissimum locum, ne nos patereris requiescere? Quid porro ad rem pertinet, si dixero Licham Tarentinum esse dominum huiusce nauigii, qui Tryphaenam exulem Tarentum ferat?

Ah, então era esta - vociferou ele - a veneta que trazias? Assim que estivéssemos instalados no canto mais retirado, debaixo da coberta do navio, tu não nos deixares pregar olho! Que adianta ao caso, se eu disser que o dono deste barco é Licas de Tarento, que a Tarento leva Trifena, a desterrada?

A revelação atingiu-os como um raio fulminante. Não havia salvação aparente. Eumolpo tinha-os atraído ao antro do Ciclope, ao domínio dos seus piores inimigos: Licas e Trifena. A esperança evasiva do espaço aberto do mar tinha-se subitamente confinado à estreiteza do barco de Licas — o qual, à imagem do que acontecera já com a Cena de Trimalquião, em breve se revelaria uma micrópolis autocrata, com a agravante de estar prestes a ser sacudida por um conflito civil. Só lhes restava apelar à piedade do poeta, companheiro de letras (101.2). Contudo Eumolpo resistia ao apelo, sem ver justificação para tal dramatismo, enquanto procurava dar mais informações sobre o proprietário da embarcação, para se certificar de que falavam de pessoas diferentes (101.4):

Lichas Tarentinus, homo uerecundissimus et non tantum huius nauigii dominus quod regit, sed fundorum etiam aliquot et familiae negotiantis, onus deferendum ad mercatum conducit.

Licas de Tarento, homem de muito respeito, e que não é só dono deste barco que governa, como também senhor de algumas propriedades e de uma casa de comércio, e que trata o transporte de cargas para o mercado.

O passo torna claro o poder de Licas, já adivinhado pelo medo que infunde em Encólpio e Gíton, embora este também possa ser explicado pela falta que os dois jovens haviam cometido e pela possível crueldade do capitão ${ }^{35}$. Eumolpo enuncia vários sinais que espelhavam a importância de Licas - a sua respeitabilidade social, a riqueza que possuía e a atividade de armador a que se dedicava - confirmando assim involuntariamente que era mesmo aquela pessoa de quem Encólpio e Gíton fugiam. Perante este cenário, urgia agora descobrir uma forma de os jovens escaparem à vista destes inimigos. Vários planos são propostos e

${ }^{35}$ Com efeito, uma das interpretações para o nome de Licas é a de 'cruel'. Ele, contudo, afirma não ter esse defeito (106.3). Cf. Walsh 1970: 99; Barchiesi 1984: 169; Schmeling 2011: 400-401. 
Macroespaço e microespaço no Satyricon de Petrónio: a narrativa de viagens e a tensão entre espaço aberto e fechado

rejeitados, acabando, por fim, por escolher exatamente o que porá a descoberto o seu disfarce. Com efeito, decidem vestir a pele de escravos fugitivos e têm, para isso, de se despojar das suas cabeleiras, gesto que constitui um voto supremo dos náufragos e, por tal motivo, de mau agoiro ${ }^{36}$. É neste ato que são surpreendidos por um passageiro enjoado (103.5-6), que, de manhã, os denuncia ao capitão (104.5).

Mostrando o seu caráter totalitário e inflexível, Licas decide castigar os faltosos com boa dose de vergastadas e é nesse momento que se descobre a verdadeira identidade de Encólpio e de Gíton (105.5-11). Os ânimos exaltam-se e os passageiros dividem-se em duas fações, fazendo com que a micrópolis do barco entre num cenário de contenda intestina: uns apoiam, outros atacam os impostores. Algumas feridas ligeiras começam a aparecer, até que a intervenção radical de Gíton, seguido de Trifena e do piloto do barco (108.9-14), põe fim à peleja. Adivinhando a oportunidade, Eumolpo aproveita para se autoproclamar árbitro e negociador autorizado (dux Eumolpos, 109.1) dos termos da paz, definindo assim as linhas de uma nova ordem social. Na sequência dessa intervenção, o macroespaço marítimo e o microespaço recriado no interior do barco afinam, momentaneamente, pela mesma imagem de paz social.

Com os ânimos arrefecidos, a calmaria do mar convida, igualmente, à confraternização. Come-se, bebe-se e não faltam, sequer, as histórias picantes que despertam os apetites e as risadas sonoras. Mas, entretanto, o céu carregara o semblante e o mar respondeu com agitação crescente ao desafio das nuvens e dos ventos. Vão seria o esforço humano: o barco baloiçava, como frágil folha, segundo o capricho das ondas. O naufrágio era inevitável. Licas, o capitão, não foi o último a abandonar o barco - como ditava a tradição —, mas antes o primeiro. O vento arrojou-o ao mar e logo uma onda lhe deu o abraço letal (114.6). Navio, equipagem e passageiros, todos se tornaram presa das águas ${ }^{37}$. E mais tarde, hão de ser os inimigos confessos de Licas, amolecidos embora por sentimentos humanitários que o momento despertou, quem lhe garantirá umas improvisadas honrarias fúnebres.

A tensão entre macroespaço e microespaço é assim dissolvida pela força do mar, que a todos coloca em idêntico patamar de fragilidade humana, preparando

${ }^{36}$ Já antes tinha havido uma referência à possibilidade do naufrágio (101.7). Curiosamente será esse desastre a pôr fim à aventura com Licas e Trifena. A ocorrência de um naufrágio estava dentro da tradição do romance grego, que esta obra parcialmente parodia. Sobre a relação entre o ato de cortar o cabelo e o risco do naufrágio, vide Scarola 1986. Sobre este tópico e em especial sobre o poema paródico que Eumolpo recita, dirigido a quem perdeu o cabelo (109.9-10), vide Setaioli 2011: 177-191.

${ }^{37}$ Licas é o único de quem se narra expressamente a morte. Trifena é recolhida em salva-vidas pelos escravos (114.7) e outros passageiros conseguem auxílio de uns pescadores (114.14). Este tratamento diferenciado acaba por acentuar o isolamento de Eumolpo e o simbolismo da sua queda. 
igualmente o caminho para um novo enquadramento narrativo e uma nova existência (fictícia) das personagens sobreviventes.

\subsection{Eumolpo: o macroespaço aberto como expressão de impudico alheamento ético e social}

Durante a situação extrema que marcou o final da seç̧ão anterior, Eumolpo tenta compor um epitáfio em honra do falecido Licas, espraiando o olhar pelo horizonte, eventualmente em busca de inspiração. Tal atitude seria normal num poeta e, por conseguinte, o seu significado pode esgotar-se nessa interpretação mais imediata. Mas talvez, no seu íntimo, o Bom Cantor se preparasse para a possibilidade de vir, também ele, a protagonizar um desfecho semelhante, como viria de facto a acontecer algum tempo depois. $\mathrm{Na}$ realidade, uma vez refeitos do susto do naufrágio, os sobreviventes metem-se ao caminho e, horas depois, avistam uma cidade, cuja identidade lhes é desconhecida. Obtêm então de certo uilicus a explicação de que se trata de Crotona, centro urbano outrora florescente, mas agora infestado de heredipetae (116.1-9), estando assim criadas as condições para entrar no derradeiro macroespaço da obra.

Eumolpo vê nesta praga dos 'caçadores de heranças' a oportunidade ideal para inverter, em termos paródicos, a lógica inerente a esta forma de exploração social, transformando os captatores em captati. A fim de pôr o plano em ação, necessita da conivência dos companheiros (Córax, Encólpio e Gíton), que prontamente aceitam fazer o papel de escravos de Eumolpo e, assim, contribuir para a ficção engendrada ${ }^{38}$. Na montagem da comédia, nenhum pormenor é descurado (117.6-8):

Post peractum sacramentum seruiliter ficti dominum consalutamus, elatumque ab Eumolpo filium pariter condiscimus, iuuenem ingentis eloquentiae et spei, ideoque de ciuitate sua miserrimum senem exisse, ne aut clientes sodalesque filii sui aut sepulcrum quotidie causam lacrimarum cerneret. Accessisse buic tristitiae proximum naufragium, quo amplius uicies sestertium amiserit; nec illum iactura moueri, sed destitutum ministerio non agnoscere dignitatem suam. Praeterea habere in Africa trecenties sestertium fundis nominibusque depositum; nam familiam quidem tam magnam per agros Numidiae esse sparsam, ut possit uel Carthaginem capere.

Depois de prestarmos juramento, disfarçámo-nos de escravos, saudámos em coro o nosso amo e aprendemos todos a mesma lição: Eumolpo acabara de perder um filho, jovem de grande eloquência e muito promissor. Por isso, o pobre do velho decidira abandonar a cidade onde habitava, para que nem os amigos e companheiros do filho, nem a visão do seu túmulo fossem, cada 1997.

${ }^{38}$ Para a leitura deste episódio à luz da estratégia de encenação de uma comédia, vide Leão 
Macroespaço e microespaço no Satyricon de Petrónio: a narrativa de viagens e a tensão entre espaço aberto e fechado

dia, causa de lágrimas. Acrescia a esta desgraça o naufrágio recente, onde perdera mais de dois milhões de sestércios; não o perturbava tanto o prejuízo como a incapacidade de tornar reconhecida a sua posição, agora que estava sem servidores. Possuía, ainda, em África, trinta milhões de sestércios em propriedades e em títulos de crédito. E quanto à criadagem, era tanta a que tinha espalhada pelas suas terras da Numídia, que até poderia tomar Cartago de assalto.

O plano tinha sido cuidadosamente pensado para ir ao encontro das expectativas que os heredipetae alimentavam relativamente a novas presas ${ }^{39}$ : primeiro, a perda recente do filho, desgosto ainda mais pungente, porquanto havia que tomar em conta as promissoras qualidades do falecido; a mágoa inconsolável, que levara o pai a evitar tudo o que pudesse avivar a recordação da tragédia; a decisão de viajar para espairecer, não contando que a sorte, uma vez mais, the seria desfavorável, acrescentando às suas desgraças o agravo de um naufrágio recente. Até aqui, a invenção procurava tornar o episódio verosímil e espevitar o interesse dos heredipetae, na ânsia, certamente, de que estes começos auspiciosos se vissem confirmados pelo fator mais importante: a desejada riqueza que pudesse servir de saque. E ela aí estava, nédia e luzidia: a narrativa inventada deixava claro que, apesar das avultadas perdas no naufrágio, os bens do velho atingiam ainda proporções quase lendárias. $\mathrm{O}$ cozinhado tinha todos os ingredientes para agradar aos captatores, que não tardaram a morder o isco (124.2-4).

Embora a fortuna e poder de Eumolpo comecem por ser fictícios, a verdade é que, pouco tempo decorrido, se tornam reais, em consequência das liberalidades dos caçadores de heranças. O próprio Encólpio, mais alegre e viçoso com a vida fácil que agora levava, o reconhece claramente (125.1):

Eumolpus felicitate plenus prioris fortunae esset oblitus adeo ut $\dagger$ suis $\dagger$ iactaret neminem gratiae suae ibi posse resistere impuneque suos, si quid deliquissent, beneficio amicorum laturos.

Eumolpo, inchado com a presente abundância, tinha-se esquecido das misérias passadas, a ponto de se vangloriar aos da casa de que ninguém ali poderia escapar à sua influência e de que, se eles cometessem algum delito, ficariam impunes, graças à intervenção dos seus amigos.

Mas o próprio Encólpio, logo a seguir, dá expressão ao temor de que a sorte deixe de lhes ser favorável e o engano se torne conhecido (125.3-4). Efetivamente,

${ }^{39}$ De acordo com a informação previamente facultada pelo uilicus (116.7-8): em termos simples, só obtinha consideração social quem fosse rico e não tivesse parentes/herdeiros próximos. Melhor ainda se fosse velho, doente e com a morte à vista, pois menor seria o investimento de tempo dos heredipetae até obterem proveito. 
a situação altera-se, talvez porque Eumolpo não retribui a generosidade dos heredipetae e estes começam a refrear as larguezas (141.1), ou então porque o estado de saúde do velho se teria degradado mesmo. Inicialmente, a doença fazia parte da ficção criada (117.9 e 140.6-9), pelo que poderia dar-se o caso de o velho estar somente a ganhar tempo até vir a melhor oportunidade para se pôr em fuga, juntamente com os mais diretos colaboradores. Mas a hipótese de que, desta vez, a debilidade física seria real está mais de acordo com o modelo analisado para Trimalquião e Licas, pois estabelece um paralelo com o encerramento das aventuras na Graeca urbs e no mar. A ser assim, o testamento de Eumolpo constituiria a sua derradeira e maior falácia. Embora seja um episódio bem conhecido, vale a pena evocar os termos em que está elaborado (141.2):

Omnes qui in testamento meo legata habent, praeter libertos meos, hac condicione percipient quae dedi, si corpus meum in partes conciderint et, astante populo, comederint.

Todos os que são contemplados no meu testamento, à exceção dos meus libertos, só entrarão na posse dos bens que lhes leguei com esta condição: que cortem em pedaços o meu corpo e, na presença do povo, o devorem.

Aos que se afadigavam à sua volta, na ânsia de conseguirem presa de vulto, mais não deixará do que o corpo velho, curtido pelos anos, e a consciência de terem sido enganados por quem projetavam burlar. E cegava-os de tal forma a miragem da riqueza de Eumolpo que bem depressa houve quem estivesse disposto a seguir a cláusula do testamento (141.5). A situação é ainda mais significativa se for tido em consideração que este último episódio acontece em Crotona, antigo bastião do pitagorismo. Segundo as palavras do uilicus (116.9), a cidade, infestada pela praga dos caçadores de heranças, assemelhava-se a um campo semeado de morte, estabelecendo assim um profundo contraste de expectativas, uma vez que o simples contacto com a morte levantava reservas aos pitagóricos, que de resto eram partidários do vegetarianismo ${ }^{40}$. Em plena inversão desse comportamento, os Crotoniatas não só se alimentam de carne (136.1; 137.12) como vão mais longe: levam a avidez pelo dinheiro ao ponto de não recuarem perante uma condição que pressupõe, para ser satisfeita, a antropofagia. Mesmo admitindo que Petrónio esteja a parodiar um topos da retórica, torna-se difícil não considerar profundamente trágica e pessimista a cena final do Satyricon.

${ }^{40}$ Cf. Nardomarino 1990: 57: «L' idea della morte, tanto distante dall' ambiente pitagorico (si ricordi che agli iniziati non era consentito prendere parte ai funerali), diviene onnipresente nella Crotone di Petronio.» Vide ainda Fedeli 1987, esp. 20-21. Para a leitura da representação de Crotona enquanto distopia pitagórica, vide Teixeira 2009. Sobre o pitagorismo enquanto categoria historiográfica, vide Cornelli 2013. 
Macroespaço e microespaço no Satyricon de Petrónio: a narrativa de viagens e a tensão entre espaço aberto e fechado

Por outro lado, ao salientar que esse ato tem de ser feito em público (astante populo), Petrónio sublinha igualmente que, por oposição ao que acontecia na Graeca urbs e no episódio de Licas, a aventura em Crotona é marcada preferencialmente pelo macroespaço aberto ${ }^{41}$, destacando-se desta forma que o universo dos heredipetatae e das suas vítimas constitui não tanto um engano velado, mas antes uma ficção por todos abertamente cultivada.

\section{A PORTA E A TENSÃo ENTRE O ESPAÇO INTERIOR E O EXTERIOR: A VER- TIGEM DO VOYEURISMO}

Apesar de ser um cenário dominado pelo espaço aberto, na aventura em Crotona verifica-se também a utilização simbólica da porta enquanto fronteira ténue que permite definir dimensões mais restritas de microespaço. É esse último aspeto que será brevemente evocado nesta parte final da análise, à luz da dinâmica entre espaço interior e exterior e da relação que estabelece com o tema do voyeurismo.

O topos do voyeurismo é bastante recorrente no Satyricon e a tentação de espiar os outros verifica-se, em especial, na forma de caracterizar a atuação dos scholastici e das figuras com as quais eles se cruzam. Embora o estudo do voyeurismo das personagens humanas não constitua o motivo central da presente reflexão, valerá ainda assim evocar alguns exemplos que possam ilustrar a forma insistente como o tópico aparece evocado, sendo conjugado em especial com o tema da porta, precisamente enquanto meio de transição e mecanismo que permite circunscrever pequenas células de microespaço íntimo, criando muitas vezes uma falsa ilusão de segurança ${ }^{42}$.

Essa ambivalência da porta encontra-se de facto presente logo nas primeiras cenas do Satyricon, mais concretamente no episódio do Foro. Com efeito, Ascilto, Gíton e Encólpio regressam rapidamente à estalagem onde se encontravam hospedados, na expectativa de poderem aí celebrar, de portas bem cerradas, a recuperação da túnica com as moedas perdidas, mas a tranca que os isolava do exterior, dando-lhes uma aparência de resguardo, desprende-se por si mesma e permite a entrada intempestiva de Quartila (15.8-16.2), que os irá arrastar para aventuras mais desgastantes do que prazenteiras.

${ }^{41}$ Perspetiva diferente em Teixeira 2008: 79-89, a qual defende que, como um todo, Crotona funciona como "a closed universe - the city of the heredipetae" (p. 79).

${ }^{42}$ Embora seja ancilar para os objetivos deste estudo, vale a pena referir a chamada "Warren Cup", uma taça de prata assim denominada em homenagem ao seu primeiro possuidor em tempos modernos. Esta peça trata cenas de homoerotismo, com a particularidade de numa delas haver a sugestão de voyeurismo representado por uma porta entreaberta através da qual alguém observa a relação entre os amantes. A taça encontra-se no British Museum e é datável da primeira metade do séc. I da Era cristã, estando por conseguinte próxima da data de composição do Satyricon, em época neroniana. Esta datação tradicional da obra petroniana é amplamente aceite pela comunidade científica, embora não de forma unânime. Sobre esta questão, vide Leão 1998: 19-31. 
É precisamente no decurso de um dos jogos de lascívia inventados pela sacerdotisa de Priapo que o motivo da porta associada ao voyeurismo e à devassa do microespaço da privacidade se destacam de maneira particularmente clara, durante a celebração das núpcias farsescas de Gíton e Pâniquis. A cena passa-se no quarto de dormir, portanto num local reservado à intimidade, mas tudo é espiado através de uma fenda na porta, descaradamente alargada, para servir de estímulo a Quartila no jogo erótico com Encólpio (26.4-5).

Uma outra referência ao voyeurismo, também num contexto marcadamente sexual, ocorre de novo na parte final da obra, já em Crotona, na paródia à ética educativa protagonizada por Filomela e por Eumolpo, o pretenso pedagogo dos filhos daquela falsa matrona (140.1-11). No decurso do episódio, há um demorado recurso ao expediente do buraco da fechadura (140.11), por onde um dos filhos de Filomela espreitava o envolvimento erótico da irmã com o velho Eumolpo - cuja proficiência a nível sexual sublinharia, por contraste, o desânimo e impotência de Encólpio/Polieno.

No episódio do Foro inicialmente evocado, a abertura intempestiva das portas acentua o sentimento de insegurança que permeia o ambiente da obra, tanto a nível do macroespaço (e.g. o mar) como do microespaço mais reduzido. Nos jogos eróticos, porém, a devassa da privacidade atenua essa conotação negativa, privilegiando antes estratégias de lascívia e de descontrolada sensualidade ${ }^{43}$.

Ambos os temas contribuem, porém, para sublinhar como as categorias de espaço aberto e fechado, de interior e exterior, de mobilidade e recolhimento, se enquadram numa visão mais ampla do universo recriado por esta obra da época neroniana, acentuando um sentimento de insegurança e de certa falência do papel civilizador de uma Roma universalista e aberta, construída à volta do ideal da pax Romana e do governo augustano.

${ }^{43}$ Para outros exemplos onde a porta assume esta função de separar dois mundos, conjugada com a ideia de uma falsa segurança, de isolamento e de invasão da privacidade, vide 11.1-4; 63.1-64.1; 91.3-4; 92.1-3; 94.7-8; 95.7-9; 96.1-4; 97.7-8; 98.2. 
Macroespaço e microespaço no Satyricon de Petrónio: a narrativa de viagens e a tensão entre espaço aberto e fechado

\section{REFERÊNCIAS BIBLIOGRÁFICAS}

Aiardi, A. (1978), "Per un'interpretazione della Domus Aurea", PP 33: 90-103.

Anderson, G. (1981), “Trimalchio at Sousa-on-sea”, AJPh 102: 50-53.

Baldwin, B. (1978), “Trimalchio's domestic staff”, AClass 21: 87-97.

Barchiesi, A. (1984), "Il nome di Lica e la poetica dei nomi in Petronio", $M D$ 12, 169-175.

Benario, H. W. (1975), "Augustus princeps", $A N R W$ II. 2: 75-85.

Blaison, M. (1998), "Suétone et l' ekphrasis de la Domus Aurea", Latomus 57: 617-624.

Brandão, J. L. (2009), "A ekphrasis suetoniana da Domus aurea", in F. Oliveira, C. Teixeira e P. B. Dias (Coords.), Espaços e Paisagens. Antiguidade Clássica e Heranças Contemporâneas vol. 1 Linguas e Literaturas. Grécia e Roma. Coimbra, 223-230.

Brandão, J. L. (2012), "Marcial e a Urbe: o meio físico e histórico-social dos Epigramas" in C. Pimentel, J. L. Brandão e Paolo Fedeli (coords.), O poeta e a cidade no mundo romano. Coimbra, 135-175.

Castorina, E. (1973), "La lingua di Petronio e la figura di Trimalchione", SicGymn 26: 18-40.

Cornelli, G. (2013), In Search of Pythagoreanism. Pythagoreanism as an Historiographical Category. Berlin.

Fedeli, P. (1987), "Petronio: Crotone o il mondo alla rovescia", Aufidus 1: 3-34.

Ferreira, J. R. e Ferreira, L. N. (2009), As Sete Maravilhas do Mundo Antigo: fontes, fantasias e reconstituições. Lisboa.

Fitzgerald, W. (2007), Martial. The World of the Epigram. Chicago.

Garnsey, P. e Saller, R. (1991), The Roman Empire. Economy, Society and Culture, Berkeley, 1987; trad. esp. El Imperio romano, economía, sociedad y cultura. Barcelona, 1991.

Grimal, P. (1955), "Sur deux mots de Néron": AFLT Pallas 3: 15-20.

Guillén, J. (2009), Vrbs Roma. Vida y costumbres de los romanos. IV. Constituición $y$ desarrolo de la sociedade. Salamanca, $2^{\mathrm{a}} \mathrm{ed}$.

Leão, D. F. (1997), "Satyricon (117): encenação de uma comédia”, Boletim de Estudos Clássicos 27: 38-44.

Leão, D. F. (1998), As ironias da Fortuna. Sátira e moralidade no 'Satyricon' de Petrónio. Lisboa.

Leão, D. F. (2004), "Zoilo e Trimalquião: duas variações sobre o tema do novo-rico", in C. S. Pimentel, D. F. Leão e J. L. Brandão (eds.), Toto notus in orbe Martialis. Marcial 1900 anos após a sua morte. Coimbra e Lisboa, 191-208. 
Leão, D. F. (2006), Petrónio. Satyricon. Tradução do latim e introdução. Lisboa, $2^{\mathrm{a}} \mathrm{ed}$.

Leão, D. F. (2013), "Poder, sabedoria e finitude no Satyricon de Petrónio", in F. V. Cerqueira, A. T. Gonçalves, E. B. Medeiros e D. F. Leão (coords.), Saberes e poderes no Mundo Antigo. Vol. II. Coimbra, 33-52.

Mantas, V. (2002), "Libertos e escravos na cidade luso-romana de Ammaia", Ibn Marúan 12: 49-68.

Mantas, V. (2005), “Os magistrados Olisiponenses do período romano”, História das figuras do poder. Colecção Turres Veteras VII. Torres Vedras, 21-56.

Mantas, V. (2010), “Epigrafia, notáveis e estatuto urbano”, Conimbriga 49: 15-39.

Martin, R. (1988), “La Cena Trimalchionis: les trois niveaux d'un festin”, BAGB: 232-247.

Morford, M. (1968), "The distortion of the Domus Aurea tradition”, Eranos 66: 158-179.

Müller, K. e Ehlers, W. (1995), Petronius Satyrica. München, 4a ed.

Nardomarino, F. (1990), "Petronio, Satyricon 141: il testamento e la scelta necrofagica", Aufidus 11-12: 25-59.

Rocca-Serra, G. (1974), "Une formule cultuelle chez Suétone (Divus Augustus, 98,2)", Mélanges de philosophie, de littérature et d'bistoire ancienne offerts à P. Boyancé. Rome, 671-680.

Scarola, M. (1986), "Un naufragio da capelli (Petronio, Sat. 101-115)", AFLB 29: 39-56.

Schlant, E. (1991), "Petronius: our contemporary", Helios 18: 49-71.

Schmeling, G. (1969), “The literary use of names in Petronius' Satyricon”, RSC 17: $5-10$.

Schmeling, G. (2011) A Commentary on the Satyrica of Petronius, with the collaboration of Aldo Setaioli. Oxford.

Setaioli, A. (2011), Arbitri Nugae. Petronius'Short Poems in the Satyrica. Frankfurt.

Sullivan, J.P. (1977), The Satyricon of Petronius. A Literary Study; trad. ital. Il Satyricon di Petronio. Uno studio letterario. Firenze.

Teixeira, C. (2005), "A odisseia romanesca do Satyricon de Petrónio: a Cena Trimalcbionis", Humanitas 57: 137-157.

Teixeira, C. (2007), Estrutura da viagem na épica de Virgílio e no romance latino. Lisboa.

Teixeira, C. (2008), "Two closed universes in the Satyricon of Petronius: the Cena Trimalchionis and the city of Croton", in C. Teixeira, D. F. Leão e P. S. Ferreira, The Satyricon of Petronius: Genre, Wandering and Style. Coimbra, 59-93. 
Macroespaço e microespaço no Satyricon de Petrónio: a narrativa de viagens e a tensão entre espaço aberto e fechado

Teixeira, C. (2009), "Crotona no Satyricon de Petrónio: uma distopia pitagórica”, in M. F. Silva (coord.), Utopias e Distopias. Coimbra.

Walsh, P.G. (1970), The Roman novel. The Satyricon of Petronius and the Metamorphoses of Apuleius. Cambridge. 